\title{
TESTING OF TMR SAND MANTIS FINAL REPORT
}

\section{Krementz W. L. Daugherty}

May 2007

Robotics, Remote \& Specialty Equipment Section Engineered Equipment and Systems Directorate Savannah River National Laboratory Aiken, SC. 29808 


\title{
DISCLAIMER
}

This report was prepared by Washington Savannah River Company (WSRC) for the United States Department of Energy under Contract No. DE-AC09-96SR18500 and is an account of work performed under that contract. Neither the United States Department of Energy, nor WSRC, nor any of their employees makes any warranty, expressed or implied, or assumes any legal liability or responsibility for the accuracy, completeness, or usefulness, of any information, apparatus, or product or process disclosed herein or represents that its use will not infringe privately owned rights. Reference herein to any specific commercial product, process, or service by trademark, name, manufacturer or otherwise does not necessarily constitute or imply endorsement, recommendation, or favoring of same by WSRC or by the United States Government or any agency thereof. The views and opinions of the authors expressed herein do not necessarily state or reflect those of the United States Government or any agency thereof.

\author{
Printed in the United States of America \\ Prepared For \\ U.S. Department of Energy
}


Key Words:

Tank 19

Sludge

Erosion-Corrosion

Retention:

\section{TESTING OF TMR SAND MANTIS FINAL REPORT}

\section{Krementz \\ W. L. Daugherty}

May 2007

Robotics, Remote \& Specialty Equipment Section Engineered Equipment and Systems Directorate Savannah River National Laboratory Aiken, SC 29808 


\section{REVIEWS AND APPROVALS}

\section{AUTHOR(S):}

D. Krementz, Author, Remote \& Specialty Equipment

Date

W. L. Daugherty, Author, Materials NDE \& Consultation

Date

\section{TECHNICAL REVIEWER(S):}

J. R. Gordon, Technical Review, Remote \& Specialty Equipment

Date

K. J. Imrich, Technical Review, Materials Performance \& Corrosion Technology Date

\section{APPROVERS}

A. Fellinger, Manager, Remote \& Specialty Equipment

Date

R. L. Bickford, Manager, Materials NDE \& Consultation

Date

S. L. Marra, Manager, Robotics, Remote \& Specialty Equipment

Date

N. C. Iyer, Director, Materials Science \& Technology

Date

C. D. Banaszewski, Project Owner, Tanks 18 \& 19 Mechanical Cleaning

Date 


\section{EXECUTIVE SUMMARY}

Screening tests of Sand Mantis candidate materials selected for erosion resistance have been completed. The results of this testing identified that over a relatively short period of operation ( $<1$ hour), measurable erosion will occur in each of the candidate zoom tube materials given equal operating exposure. Additionally, this testing has shown that erosion of the rubber discharge hose directly downstream of the vehicle could be expected to limit the service life of the discharge hose. On the basis of these test results, SRNL recommends the following;

- redesign of critical system components (e.g., zoom tube, discharge hose) should be conducted to improve system characteristics relative to erosion and capitalize on the results of this testing,

- continued efforts to deploy the Sand Mantis should include testing to better define and optimize operating parameters, and gain an understanding of system dynamics,

- discontinue wear testing with the selected materials pending redesign of critical system components ( $1^{\text {st }}$ recommendation) and inclusion of other candidate materials. The final selection of additional candidate materials should be made following design changes, but might include a Stellite alloy or zirconia. 


\section{TABLE OF CONTENTS}

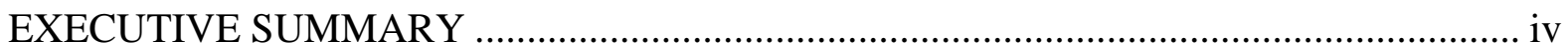

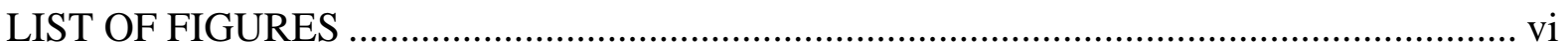

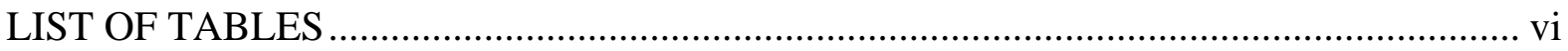

LIST OF ACRONYMS .............................................................................................. vii

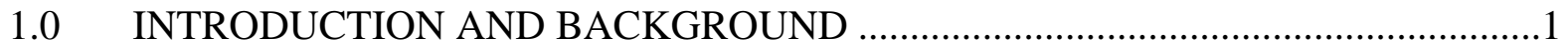

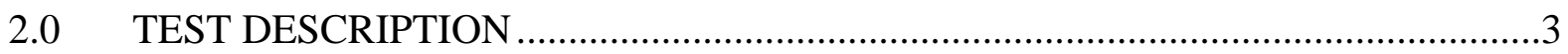

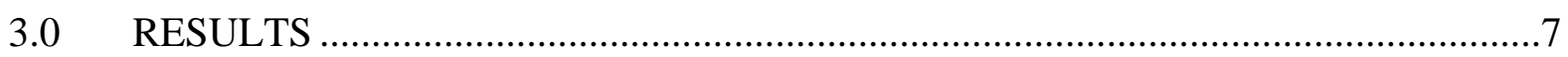

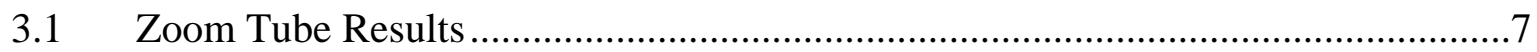

3.2 Chemical Compatibility of Zoom Tube Materials.....................................................11

$3.3 \quad$ Nozzle Results ................................................................................................

4.0 ANALYSIS OF TESTED COMPONENTS..........................................................

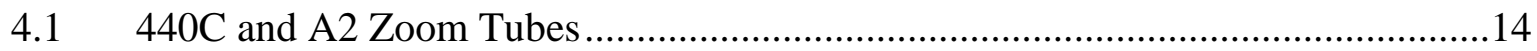

4.2 Goodyear Hose Zoom Tube...........................................................................14

$4.3 \quad$ Chemical Compatibility ......................................................................................15

4.4 Sand Mantis Performance Notes........................................................................16

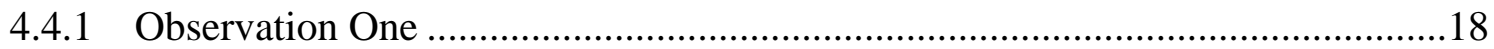

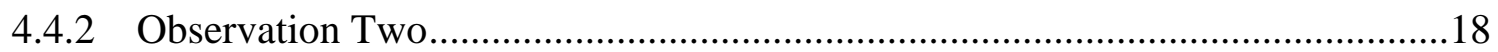

4.5 Application to Tank 19 ....................................................................................19

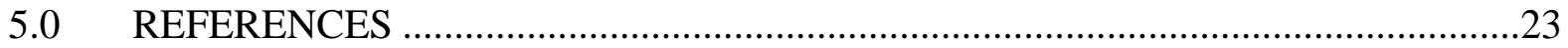




\section{LIST OF FIGURES}

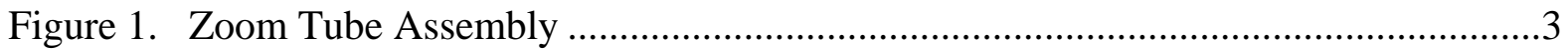

Figure 2. Weight gain for Goodyear hose sections .......................................................11

Figure 3. Nozzle 1 diamond insert (center rings) after testing showing no measurable degradation, photographed at 40X. The stainless steel face is around the edge and out of focus.

Figure 4. Nozzle 1 stainless steel insert face before and after testing, photographed at

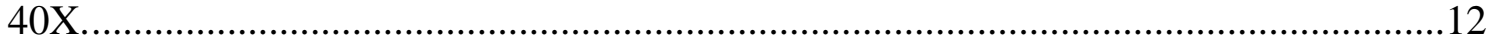

Figure 5. Wear of discharge hose following screening tests. The central white region is sand which was left embedded in the hose wall.

Figure 6. Wear of 65 -inch-long tube following screening tests.........................................17

\section{LIST OF TABLES}

Table 1. Notes and measurements for erosion tests on 440C zoom tube .............................8

Table 2. Notes and measurements for erosion tests on A2 zoom tube .................................9

Table 3. Notes and measurements for erosion tests on Goodyear hose zoom tube..............10

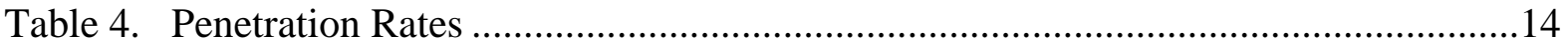




\section{LIST OF ACRONYMS}

DWPF Defense Waste Processing Facility

ID Inside diameter

LWO Liquid Waste Operations

PVC Poly vinyl chloride

SAR Slurry abrasion response

SRNL Savannah River National Laboratory

TMR Technical Mechanical Resource Associates

TTQAP Task technical \& quality assurance plan 


\subsection{INTRODUCTION AND BACKGROUND}

Liquid Waste Operations (LWO) is investigating options for the effective removal of material from Tank 19 and transfer to Tank 7. The total estimated quantity of wet solids in Tank 19 is approximately 15,000 gallons, of which the dry solids are estimated to weigh approximately 30,000 pounds [1]. Complicating the removal is the presence of a variety of objects which have been abandoned within Tank 19 over the years. The overall chemistry within the tank is highly alkaline, with an approximate $\mathrm{pH}$ of 14 . The waste solution is not significantly corrosive to the carbon steel tank walls, as evidenced by the tank history.

One of the options under consideration is the Sand Mantis remote vehicle developed by Technical Mechanical Resource Associates (TMR). It uses a 32,000 psi water nozzle(s) to create adequate vacuum to remove material from a source tank and propel the material to a receipt tank. In testing at the TMR facility in Denver, CO the Sand Mantis demonstrated a capability to transfer material through approximately 500 - 600 feet of 2” hose with a 53 foot lift to approximate waste removal and transfer from SRS High Level Waste Tank 19 to Tank 7. However, erosion of the piping directly downstream of the high pressure nozzle (the zoom tube) during the Denver testing indicated the need to identify a more erosion-resistant material. Given the chemical species present within Tank 19, the presence of erosion also raises a possibility of erosion-corrosion - a synergistic attack of material even in an environment where corrosion alone may not be significant.

Damage to the sapphire high pressure nozzle orifices was also noted during the Denver testing. This indicated a need for additional testing with a diamond nozzle insert before a nozzle service life can be estimated. The desired service life in Tank 19 is approximately 400 hours of continuous operation, based on preliminary estimates of the bulk transfer rate of the Sand Mantis.

To further explore the viability of using the Sand Mantis in Tank 19, SRNL was specifically tasked with testing of zoom tubes made of more robust materials, and characterizing the service life of a more robust diamond-insert nozzle [2]. The selection of candidate zoom tube materials was made following collaboration between SRNL, TMR and LWO. Work proceeded under task plan TTQAP-23143 [3]. This report documents results of the screening tests of three candidate zoom tube materials and a diamond-insert nozzle. 
WSRC-STI-2007-00189

This page intentionally left blank. 


\subsection{TEST DESCRIPTION}

Key elements of the Sand Mantis and associated equipment were provided to SRNL from TMR for test purposes. In addition, SRNL rented a 40,000 psi pump and provided additional hose. Testing included erosion testing of the candidate zoom tube materials, compatibility testing of Goodyear Plicord Blast hose in a high pH solution, and slurry abrasion response (SAR) testing of the other zoom tube materials in a representative chemistry. As part of the planned testing, observations relating to nozzle service life and the performance of other system components were made.

The Sand Mantis test setup centered on a high pressure stream developed by a 40,000 psi pump similar to the pump used by TMR. Most of the pertinent parts of the test setup are shown in Figure 1. A 0.034" diameter diamond orifice directs a 32,000 psi water stream into the zoom tube. A 65-inch long 1.5-inch tube downstream of the zoom tube represents the remaining length of the Sand Mantis body.

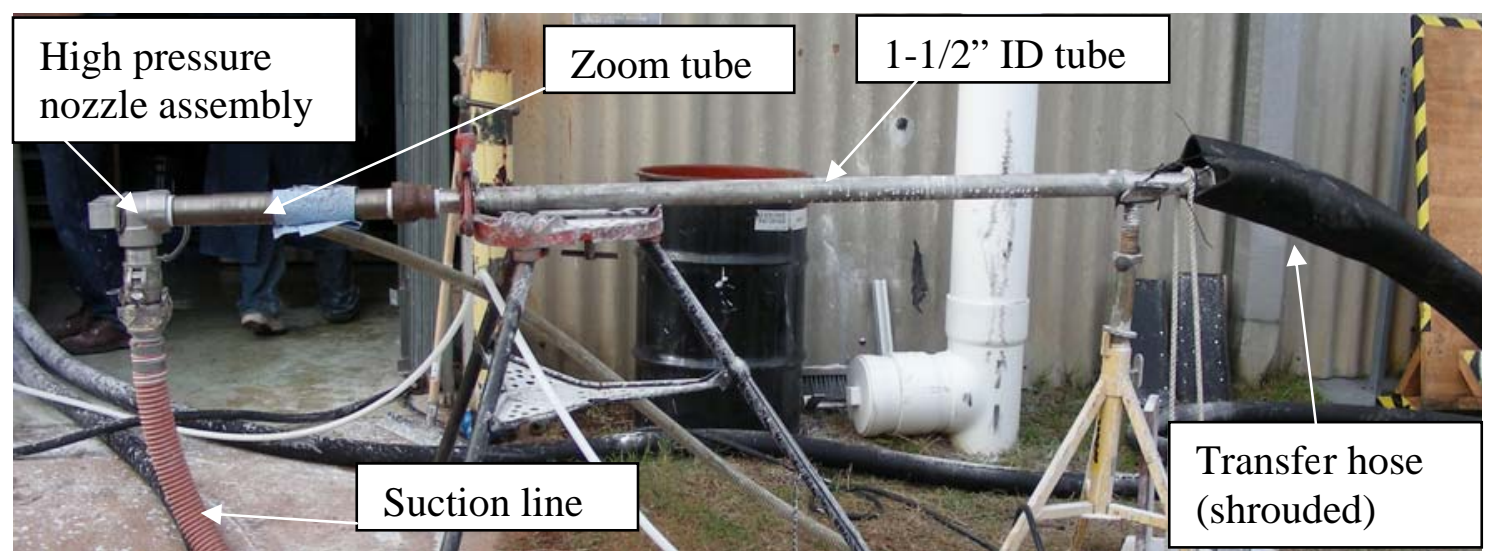

Figure 1. Zoom Tube Assembly

The 65-inch long stainless steel tube was connected to a 2-inch transfer hose, made of sections of Goodyear Allcrete Textile hose and clear PVC hose, in the following configuration (which mimics the configuration used in Denver and the expected transfer line configuration during field deployment):

1. Allcrete, 70 foot horizontal

2. PVC, 50 foot vertical upward

3. PVC, 300 foot horizontal

4. PVC, 50 foot vertical downward

5. Allcrete, 100 foot horizontal 
A suction hose enters the Sand Mantis just downstream of the high pressure water stream to transfer the sludge simulant, which was mixed and placed into a drum. The water stream and simulant were captured in a second drum.

Five candidate materials for the zoom tube were originally identified for screening tests. Materials identified included both a zirconia and a Stellite material based on known erosion performance and experience with these materials in other onsite applications (e.g. Stellite use in DWPF). However, a projected lead time of 8 weeks for each of these materials precluded their use in these screening tests. Therefore, screening tests were limited to three candidate zoom tube materials:

1. 440C stainless steel, heat treated to Rockwell C 53.

2. A2 tool steel, heat treated to Rockwell C 58.

3. Goodyear Plicord Blast two-ply hose.

The 440C and A2 zoom tubes had the same dimensions as the zoom tube tested in Denver, with an ID of 7/8 inch. The downstream end of the 440C and A2 zoom tubes were connected to the 65-inch long tube section. For the third zoom tube, a 1-inch ID section of Plicord Blast hose was inserted into a stainless steel sleeve, producing a total zoom tube length of 19 inches. The hose was retained on the downstream end by a stainless steel adapter, which attached to the 65-inch long pipe.

The solids in Tank 19 are primarily zeolite resin, which includes 65\% silicon dioxide (sand). This was approximated in the testing with a fine mesh sand, Sil-Co-Sil 125. Analysis of this product identifies 78\% is smaller than 45 microns, and 99\% is smaller that 106 microns. This simulant is expected to be a mildly conservative abrasive versus the actual tank contents, since the silicon dioxide is the most abrasive constituent of the zeolite resin. The sand was mixed with water in a ratio of 3 gallons water per 50 pounds of sand.

Prior to the first transfer, each zoom tube was photographed and weighed, the roughness and circumferential profile were measured on the conical entrance and just beyond the conical entrance, and an impression of the inlet end was made. (The Plicord Blast hose was inside a stainless steel sleeve. The conical entrance was incorporated into the sleeve. For this hose section, the straight bore section at the inlet end was measured and captured in an impression.) The impressions were made with Repro Rubber, an inspection molding compound which accurately retains its dimensions for later measurements.

All testing was performed with a single diamond-insert nozzle, which also received baseline characterization. Prior to testing, the nozzle and insert were photographed. The ID of the insert was measured using a measuring microscope, and found to be 0.0335 inch. This is in agreement with the nominal insert diameter of 0.034 inch. The nozzle was examined for wear / degradation several times during the test runs. 
During an initial trial transfer of the simulant with only 40 feet of Allcrete discharge hose, the hose was breached just downstream of the 65 inch long tube. Examination of the two $20 \mathrm{ft}$ hose sections identified several apparent defects on the ID surface, but provided no evidence that defects were present at the breach location. Details of this initial transfer and hose examination are provided in Reference 4. Subsequent tests identified that the high pressure water and simulant could wear through the Allcrete hose, with the wear rate depending on impact angle. This was observed on sections of new hose with no observable defects contributing to the wear [5]. When the discharge hose was lengthened to the $570 \mathrm{ft}$ configuration described above, the back pressure was sufficient to alter the flow regime and no further breaches of the discharge hose occurred.

Testing proceeded incrementally to provide interim inspection opportunities that would identify any developing degradation of the candidate materials. Each of the zoom tubes was used to transfer two batches of simulant. Each batch contained a total of either 800 or 1000 pounds of sand. After each batch transfer, the zoom tube was weighed and examined visually. The observed wear patterns were photographed. Impressions of the inlet end of each zoom tube were made to compare to the baseline configuration. Following the second transfer, the circumferential profile measurements were repeated.

Slurry Abrasivity Response (SAR) testing was performed by White Rock Engineering Services to characterize the compatibility of the 440C and A2 materials, from an erosion-corrosion standpoint, with the $\mathrm{pH}$ level in Tank 19 [6]. Test coupons were procured and shipped to the testing laboratory. The samples were heat treated to the same schedule as the zoom tubes. The SAR test was conducted in a slurry of UOP IONSIV 20X50 Resin with 2N sodium hydroxide, which better approximates the tank contents than the Sil-Co-Sil 125, and was readily available in small quantities. The slurry consisted of 1 part (by weight) resin and 2 parts (by weight) sodium hydroxide solution. The slurry $\mathrm{pH}$ varied from 13.3 to 13.9 .

A separate compatibility test was performed to identify the response of the Plicord Blast hose to a sodium hydroxide solution. One sample was placed in a $4.5 \mathrm{wt} \% \mathrm{NaOH}$ solution ( $\mathrm{pH} \sim 14)$. When a weight gain was observed after 2 days, a second sample was placed in water as a control. A total exposure time of 15 days was accumulated in the $\mathrm{NaOH}$ solution, while the control spent a total of 11 days in water. The weight, thickness and hardness for each sample was characterized initially, and following each of two exposure periods. 
WSRC-STI-2007-00189

This page intentionally left blank. 


\subsection{RESULTS}

\subsection{Zoom Tube Results}

Notes and measurements of the zoom tubes following each batch are summarized in Table 1 through Table 3.

After the first batch of simulant, wear was evident on each zoom tube. A groove was worn into the last several inches of the $440 \mathrm{C}$ and Goodyear hose zoom tubes. In addition, the adapter at the end of the Goodyear hose also contained a worn groove. A groove was worn near the entrance of the A2 zoom tube, extending several inches in length, and a second smaller groove was worn further downstream. The position of the grooves in the A2 zoom tube is attributed to a small metal chip that was found behind the high pressure orifice and disrupted the flow pattern for this run only.

After the second batch of simulant, additional wear was evident on the 440C and A2 zoom tubes. Due to a slight change in the nozzle orientation, a second groove was worn into the last several inches of the 440C zoom tube. Grooves of noticeable depth were also worn into the last several inches of the A2 zoom tube. A minor region of wear was also noted on the adapter at the end of the Goodyear hose zoom tube (away from the previous groove), but it was not obvious that additional wear occurred on the hose. The Goodyear hose is slightly ovalized, as shown in the profiles in Table 3. This effect was taken into account in identifying the depth of material loss after the tests.

Both the A2 and 440C zoom tubes experienced a measurable weight loss from each batch of simulant. The rubber hose experienced a weight gain, resulting from moisture absorption exceeding the amount of material loss. Moisture absorption was also noted in the chemical compatibility testing of this hose. 
Table 1. Notes and measurements for erosion tests on $440 \mathrm{C}$ zoom tube

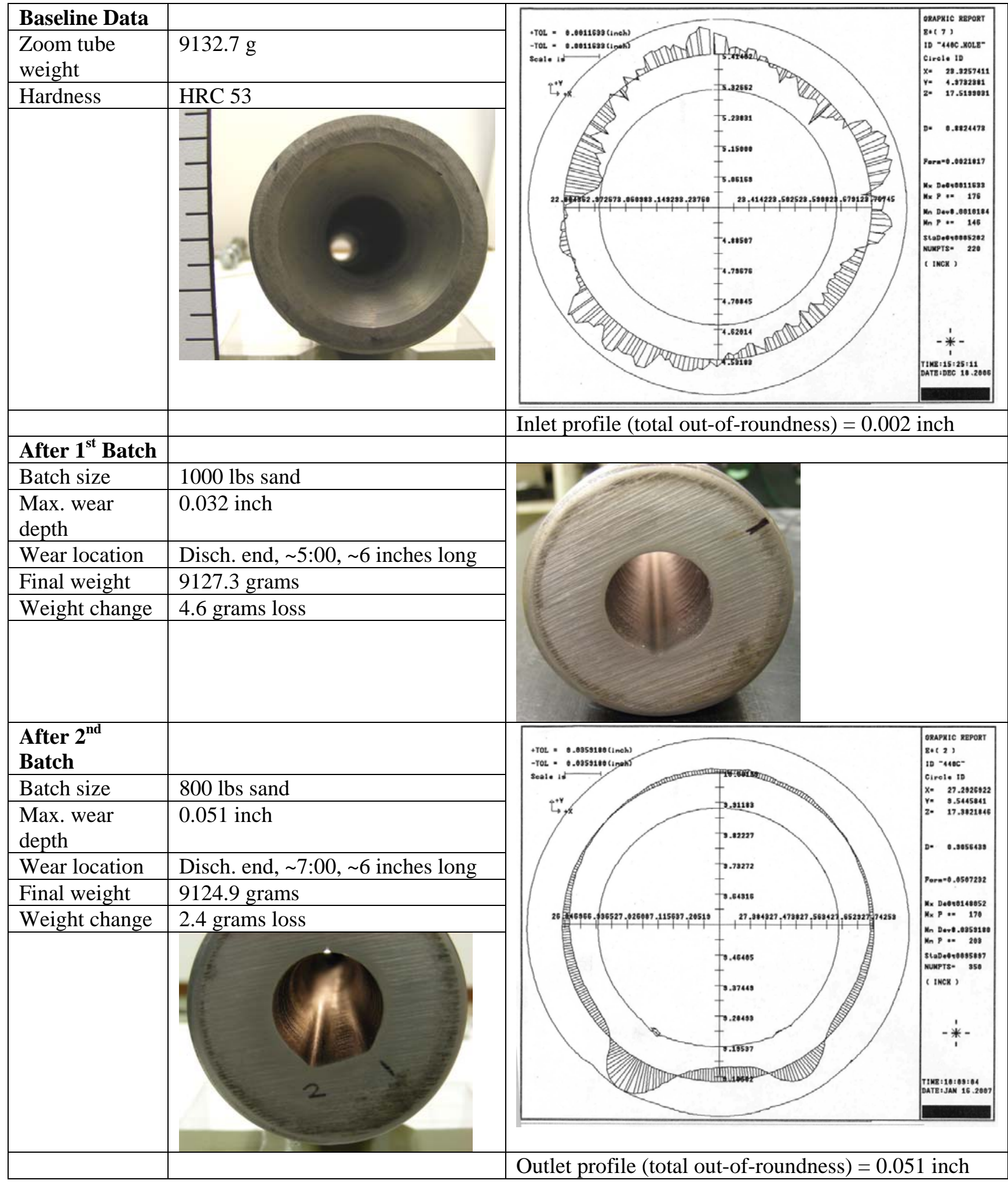


Table 2. Notes and measurements for erosion tests on A2 zoom tube

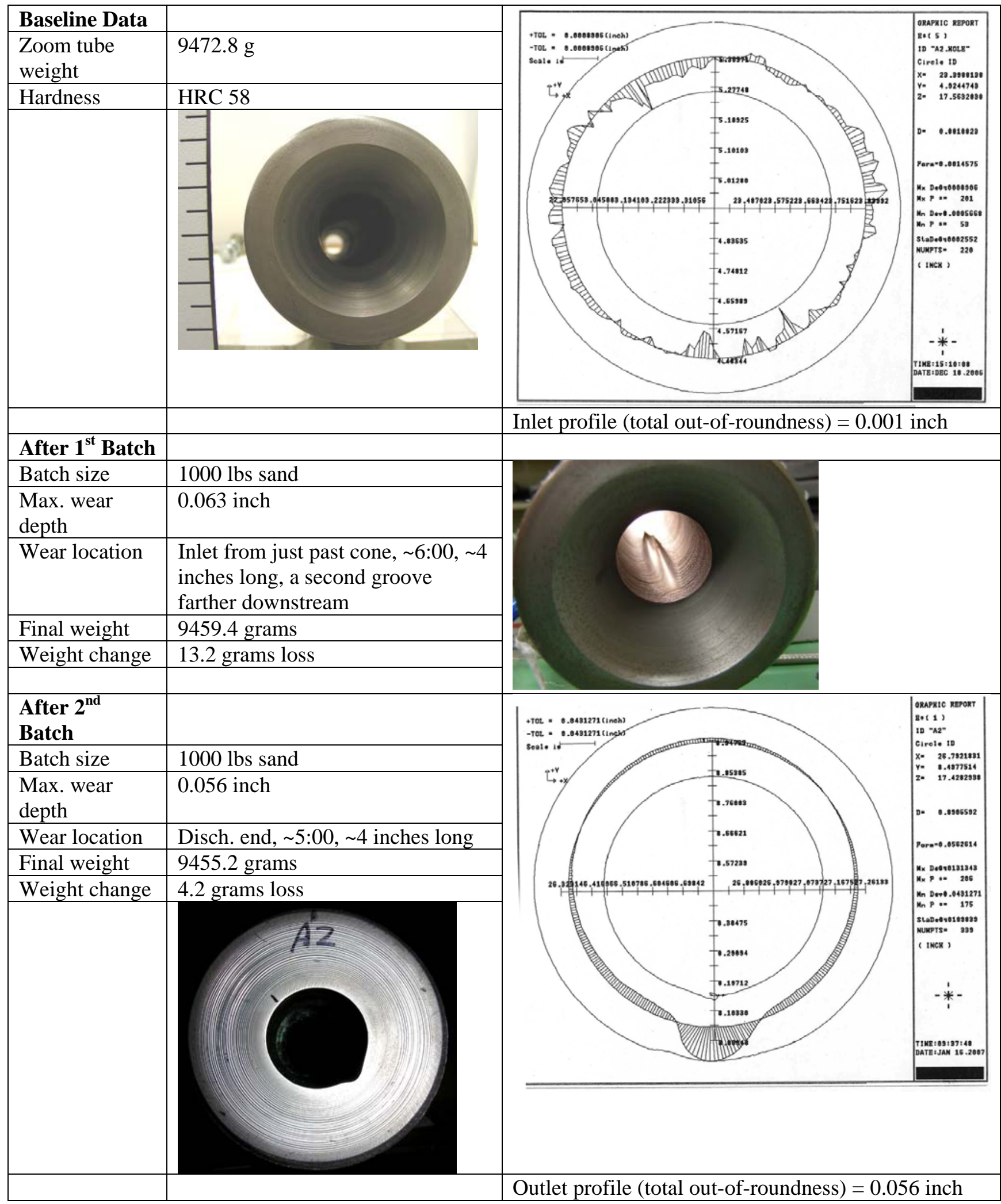


Table 3. Notes and measurements for erosion tests on Goodyear hose zoom tube

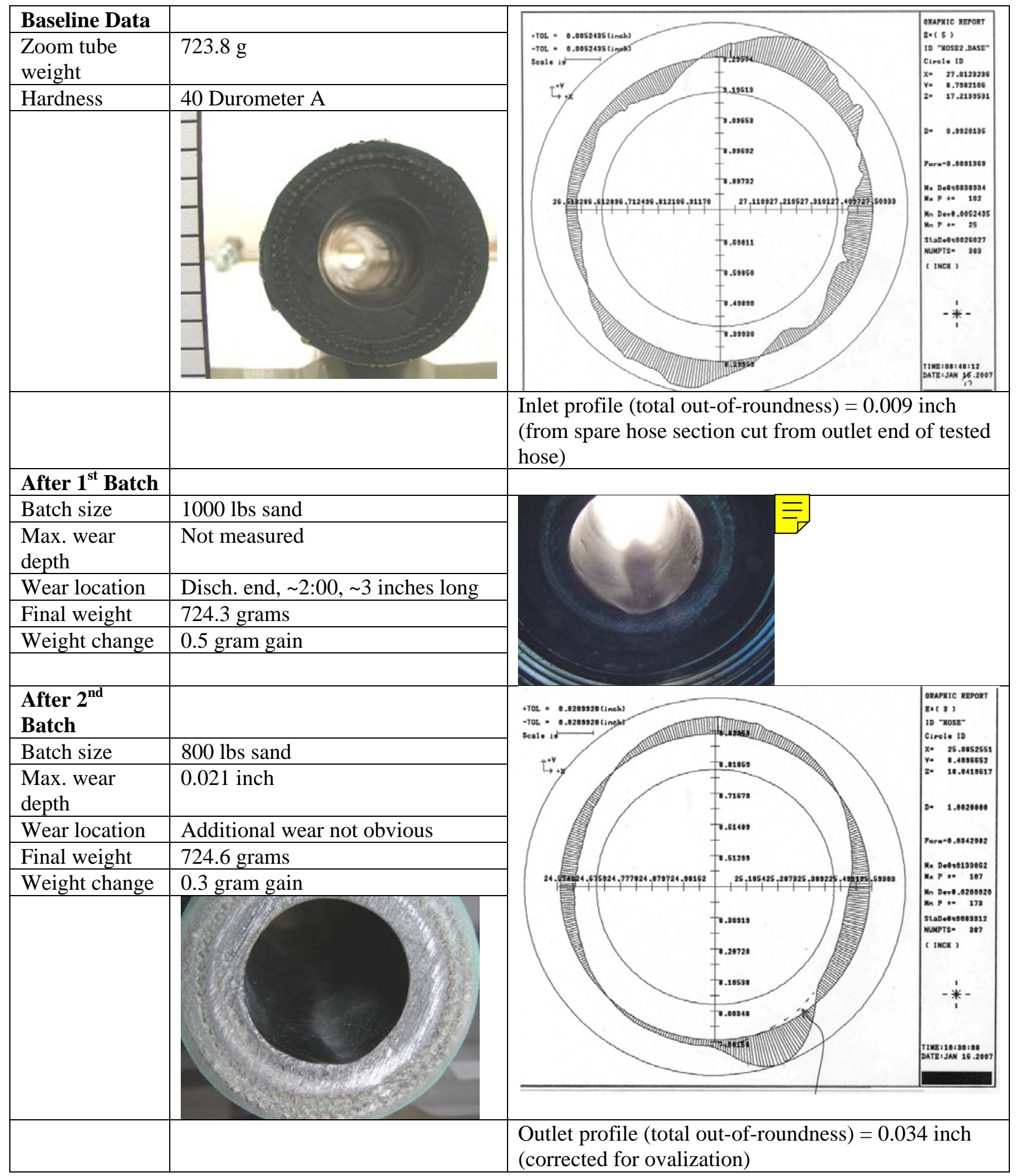




\subsection{Chemical Compatibility of Zoom Tube Materials}

The SAR number provides a relative volume loss of the sample resulting from rubbing the sample against a neoprene rubber surface while submerged in the slurry. For both materials, the slurry particle size decreased during the test, leading to a reduction in abrasivity during the test. Based on averages of two samples for each material, the SAR number is 26.9 for the 440C samples, and 36.0 for the A2 samples. SAR numbers below 50 are considered relatively nonabrasive.

Sections of the Goodyear rubber hose were immersed in $\mathrm{NaOH}$ solution or in water. Both samples experienced significant increases in weight and thickness, and a modest decrease in hardness. The changes were comparable for the two solutions ( $\mathrm{NaOH}$ and water), indicating there was no significant chemical degradation from the $\mathrm{NaOH}$. Figure 2 shows the relative weight gain for the two solutions, with an increase of $\sim 8 \%$ over a 15 day period. The majority of this weight gain appears to be almost immediate, with a much slower continuing weight increase over time. The thickness increase was $~ 2 \%$.

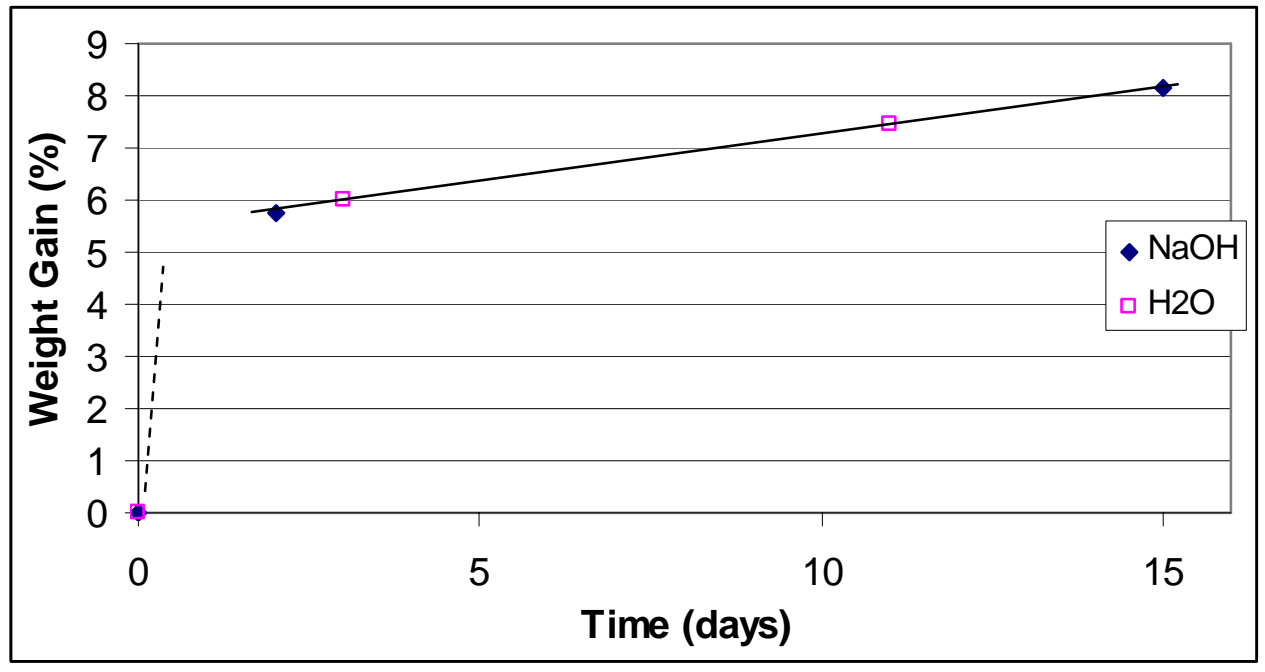

Figure 2. Weight gain for Goodyear hose sections 


\subsection{Nozzle Results}

All testing was performed with nozzle 1 . The baseline ID for the nozzle 1 insert was 0.03350 inch. A second nozzle had a baseline ID of 0.03355 inch. No wear is evident on the nozzle 1 diamond insert following testing. The inside diameter of the insert was essentially unchanged and the exit edge is visually sharp (Figure 3). However, the steel holder has experienced some wear on the discharge side. Some wear was observed prior to testing. Figure 4 shows the discharge side before and after testing. None of the observed wear on the nozzle discharge face was significant in terms of impacting performance. The testing performed was not sufficient to estimate an expected service life for the nozzle.

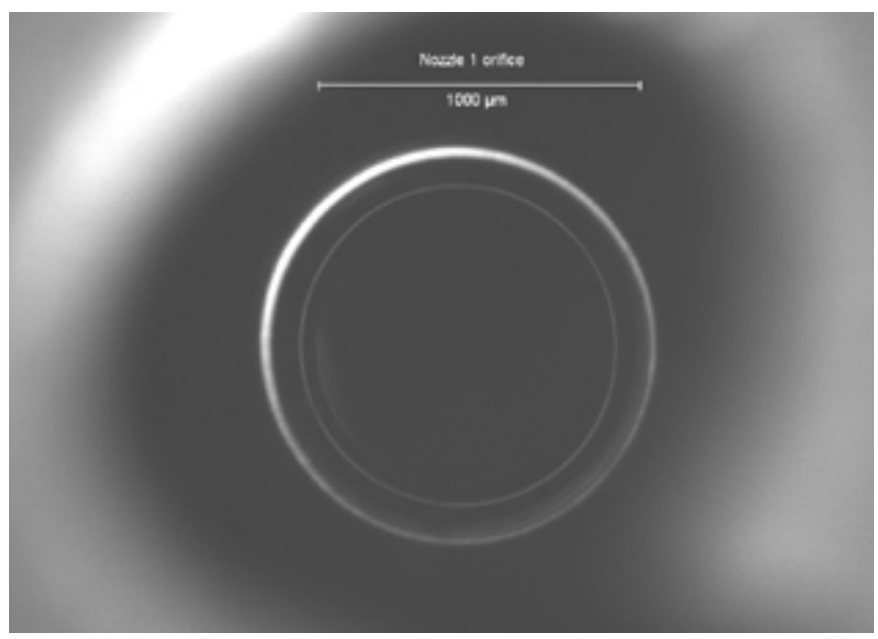

Figure 3. Nozzle 1 diamond insert (center rings) after testing showing no measurable degradation, photographed at $40 \mathrm{X}$. The stainless steel face is around the edge and out of focus.
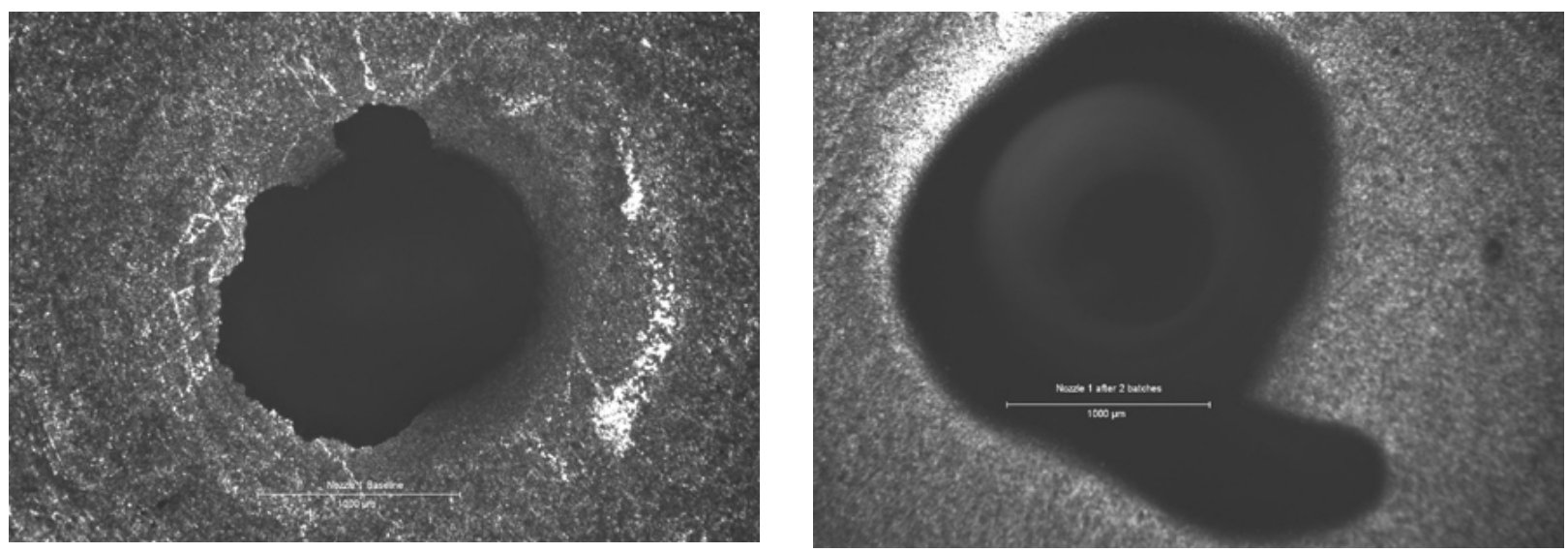

Figure 4. Nozzle 1 stainless steel insert face before and after testing, photographed at $40 \mathrm{X}$. 
WSRC-STI-2007-00189

This page intentionally left blank. 


\subsection{ANALYSIS OF TESTED COMPONENTS}

The manifold and nozzle were removed / re-installed or adjusted at several times during the testing. While care was taken to maintain the alignment of the various components, it is possible that minor variations in alignment existed. This could have a measurable effect on the aim of the water stream and the point at which it impacts any downstream components. This effect is suggested by the changing location of the observed wear patterns for each zoom tube.

\subsection{C and A2 Zoom Tubes}

For both the 440C and A2 zoom tubes, more zoom tube material was removed during the first batch than during the second batch. The weight loss for the A2 zoom tube during the first batch was more than triple that of the second batch. The magnitude of this difference suggests that material removal rates are increased if the stream is interrupted (in this case due to debris lodged in the orifice) to move the impact point of the stream closer to the nozzle.

For each run, a rate of material loss can be estimated. Since each batch led to wear in a different location of these two zoom tubes, each batch provides a separate estimate. Penetration rate is a more meaningful metric than weight loss rate since the area over which weight is lost can vary widely, and service life will be limited by wall penetration. Penetration rates are shown in Table 4.

Table 4. Penetration Rates

\begin{tabular}{|l|l|l|l|}
\hline & Max. Penetration & Simulant Amount & Penetration Rate \\
\hline 440C Batch 1 & 0.032 inch & $1000 \mathrm{lb}$ & $0.032 \mathrm{inch} / 1000 \mathrm{lb}$ \\
\hline 440C Batch 2 & 0.051 inch & $800 \mathrm{lb}$ & $0.064 \mathrm{inch} / 1000 \mathrm{lb}$ \\
\hline A2 Batch 1 & 0.063 inch & $1000 \mathrm{lb}$ & $0.063 \mathrm{inch} / 1000 \mathrm{lb}$ \\
\hline A2 Batch 2 & 0.056 inch & $1000 \mathrm{lb}$ & $0.056 \mathrm{inch} / 1000 \mathrm{lb}$ \\
\hline
\end{tabular}

\subsection{Goodyear Hose Zoom Tube}

The hose used in the erosion test was contained within a pipe section, and held securely with an adapter on the downstream end. The adapter ID is nominally the same as the hose ID, which extends the transition to the1-1/2 inch ID tube an additional 3 inches. To the extent the adapter influences the flow pattern within the hose, the wear of the hose cannot be compared directly to the wear of the other zoom tubes. The minimal wear in both the zoom tube and the adapter during the second batch indicates that the impact zone may have been downstream of the zoom tube and adapter. The nozzle and nozzle holder were removed and retorqued to ensure the correct angular orientation of the nozzle and to inspect the nozzle for wear. This reinstallation process may have moved the zone of direct impingement downstream past the zoom tube. 
The hose has a larger ID than the other zoom tubes (1 inch vs. 7/8 inch). This is expected to have the effect of moving any damage zones further downstream. The high pressure water stream expands as it moves downstream, and the point where it impacts the wall will be further downstream for a larger ID.

The maximum depth of penetration after the second batch was $0.021 \mathrm{inch}$. Comparing the photographs after each batch, it appears that most if not all of this wear occurred during the first batch. The wear rate for the hose is therefore bounded by 0.021 inch / $1000 \mathrm{lb}$ simulant. The inner wear layer of the hose is 5/16 inches thick (nominal). Approximately $7 \%$ of this thickness was penetrated with the transfer of 1000 pounds of simulant.

\subsection{Chemical Compatibility}

Literature data regarding the potential for erosion-corrosion of carbon steel in the waste tanks [7] provides some insight into the potential performance of the Sand Mantis. This reference points out that erosion-corrosion rates can be significantly reduced through standard corrosion control methods such as adding inhibitors. The waste tanks (including Tank 19) have a history of inhibitor additions to maintain the integrity of the tanks, such that the general corrosion rate of the waste tanks is essentially zero. If the corrosion component is eliminated, then erosioncorrosion rates will be reduced to just the contribution from erosion.

With the A2 and 440C zoom tube materials, general corrosion from the Tank 19 sludge should be minimal. Given the good history of the carbon steel waste tanks and the alloying additions in these materials that generally increase corrosion resistance, corrosion alone is expected to be very low. One possible exception to this line of reasoning is found in Reference 8, which identifies that 440C did not maintain its passivity in aerated slurries. The slurry $\mathrm{pH}$ was around 8, and may not be representative of higher $\mathrm{pH}$ slurries. However, the Sand Mantis produces a highly aerated mixture, and loss of passivity of the 440C could lead to measurable corrosion rates. With the additional presence of abrasive particles, erosion-corrosion could become significant.

The A2 material would be expected to avoid the potential difficulties of 440C with regards to loss of passivity, since A2 does not display active / passive behavior. In this regard, A2 would be expected to perform more like the carbon steel waste tanks in displaying essentially no corrosion.

The SAR tests indicate that the zeolite resin is not particularly abrasive against the 440C or A2 samples. This test measures the relative wear rate in a specific configuration. Wear rates under a high velocity stream impacting at a shallow angle could be very different. It is noted that the zeolite particles contain a significant percentage of silica (sand), and that the zeolite particles tend to crumble easily under impact loadings. The use of fine grain sand, with a grain size similar to the size of silica particles in zeolite, is considered a reasonable surrogate for Tank 19 sludge. In terms of erosion potential, the sand is probably a conservative surrogate (i.e., it would produce a greater erosion rate) but the degree of conservatism cannot be quantified from available information. 
The Goodyear Plicord Blast hose contains an internal layer of Tufsyn, a synthetic rubber typically used in tires. Vendor data identifies it as suitable for continuous service in $\mathrm{NaOH}$ solutions at concentrations and temperatures exceeding the Tank 19 environment. It is also acceptable in a number of other chemicals, such as sodium nitrate, sodium sulfate, sodium chloride and sulfuric acid, which contain ionic species that may also be present in Tank 19 $[9,10]$. Erosion behavior for this material may be significant in some circumstances. While this and similar hose products are marketed for handling hard abrasive materials such as sand, they are generally pumped at relatively low velocity. Under higher velocity and varying impact angles, physical damage to the material is possible. This has been noted in Neoprene, a similar material [11]. Tested in coal slurry with a 20 degree impact angle, the material was found to be very resilient to the impact of solid particles. However, it did not resist the tearing action of angular particles.

\subsection{Sand Mantis Performance Notes}

The zoom tube material testing provided an opportunity to observe the operational characteristics of the equipment. While this evaluation was not part of the test objective the testing provided an opportunity to make these observations.

An initial effort to perform the screening tests led to a rupture of the discharge pipe after approximately 7 minutes of operation. To perform the screening tests the length of discharge hose was increased significantly (from 40 to 570 feet) to match the length of hose successfully demonstrated during TMR testing in Denver. Following the screening tests, the hose was inspected and was found to have been partially penetrated in the same manner as the initial breach (Figure 5). In addition, some wear was observed inside the 65 inch long tube (Figure 6). 


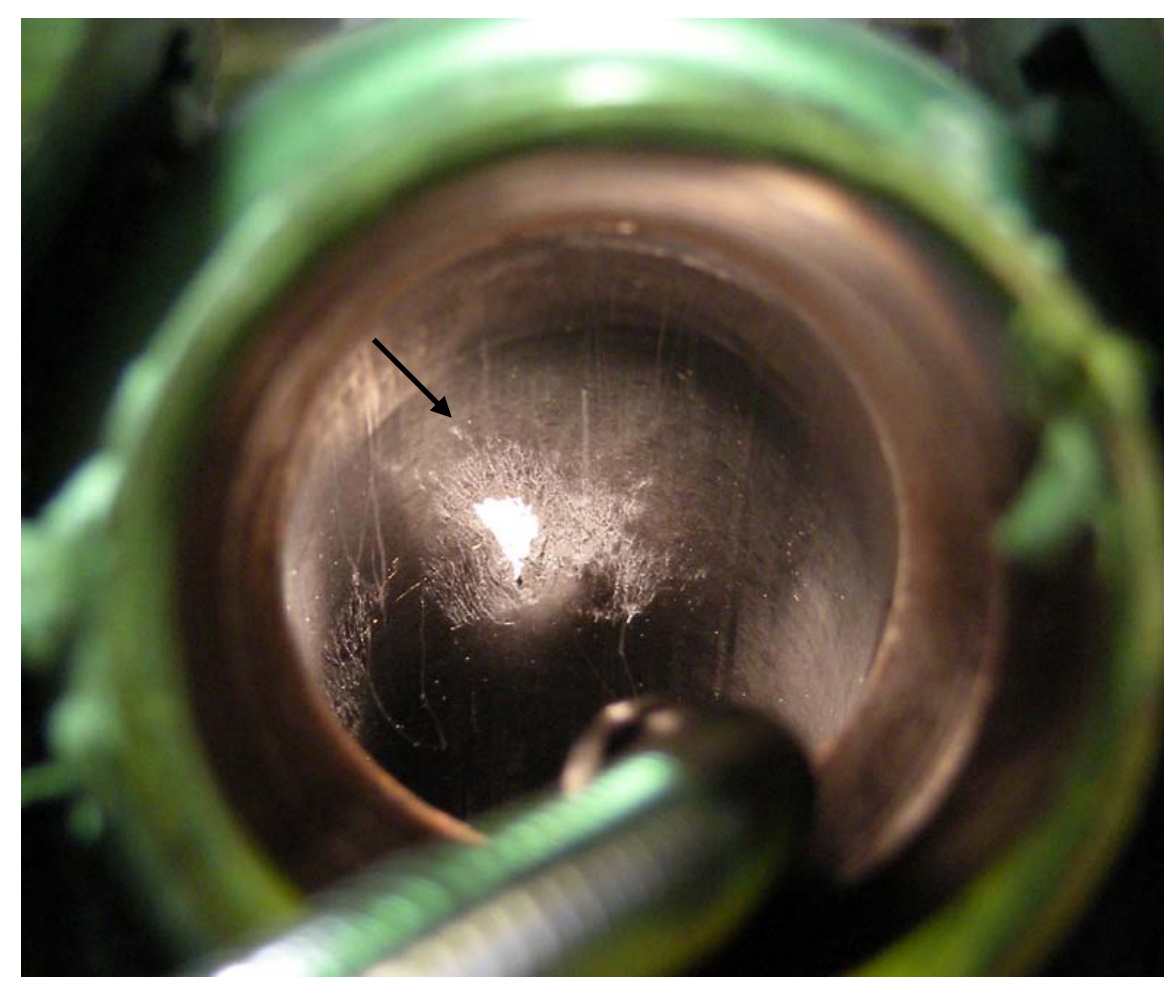

Figure 5. Wear of discharge hose following screening tests. The central white region is sand which was left embedded in the hose wall.

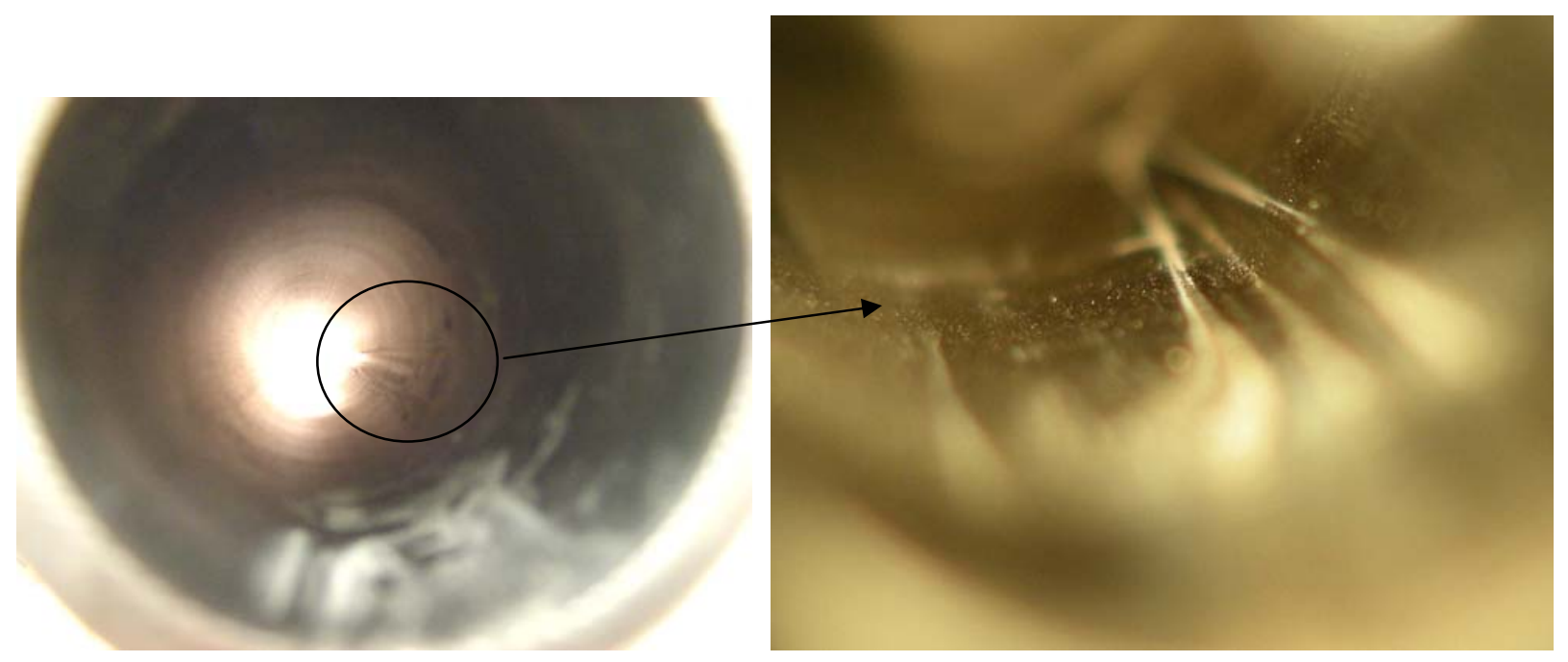

Figure 6. Wear of 65-inch-long tube following screening tests 


\subsubsection{Observation One}

Small perturbations in the system tend to create new or pronounced deviations from the expected operating conditions.

- On at least two occasions (once at SRNL and once at TMR) small bits of debris found their way to the upstream or high pressure side of the nozzle causing changes in nozzle flow that damaged the nozzle in one case, the nozzle holder in another, and drastically altered the wear pattern in the zoom tubes.

- Changes in the wear patterns found within the machine can be produced by small changes in nozzle alignment which in turn can be produced by applying a slightly different torque at any one of the connections during assembly.

- Changes in the amount of air entrained in the flow appears to drastically alter the characteristics of the flow with regard to its capacity to move material into the machine, pump material through the system, and wear or damage components.

\subsubsection{Observation Two}

The dynamics of the machine are not trivial, and for this reason, are probably not fully understood.

- Failure of the discharge hose in its initial, short, configuration demonstrated that the discharge configuration of the equipment has an influence on the pumping regime.

- The most pronounced wear patterns appeared just upstream of expansions in the piping; while there was much less wear noticeable downstream. It is inferred from this that the arrangement and geometry of these changes can influence the shape/orientation of the main jet as it flows through the machine.

- Abrasive water jet cutting machines are similar in design to the squid/zoom tube portion of the Sand Mantis in their construction from three basic components: orifice, mixing chamber, and focus tube. Abrasive water jet cutting machines also operate in a similar pressure range. It is probably not surprising then that testing of the squid/zoom tube has demonstrated its ability to remove material and damage the discharge hose. 


\subsection{Application to Tank 19}

Reference 1 develops an estimate of 15,000 gallons of wet solids remaining in Tank 19. This reference also estimates that the wet solids contain approximately 30,000 pounds of dry solids. If the wear varies linearly with the amount of solids transferred, then significantly greater wear would be predicted to transfer the 30,000 pounds of solids in Tank 19. Either 30 or 15 times as much wear as was observed in transferring 1000 or 2000 pounds of sand simulant might be expected. At this rate, it was concluded that none of the candidate materials would provide the desired erosion resistance. Accordingly, screening testing was stopped at that point.

Some effort was made to identify potential improvements through redesign of the Sand Mantis, or with alternate equipment. For example, operation of the Sand Mantis at a reduced pressure would likely produce less wear on the zoom tube and other components. However, discussions with TMR representatives identified that the Sand Mantis eductor does not transfer material in the desired transfer line configuration at less than $26 \mathrm{ksi}$. This reduction in pressure from $32 \mathrm{ksi}$ was not deemed significant enough to warrant additional erosion testing. Redesign of the zoom tube and other components was considered as well. Prior to initiating any work in this regard, TMR requested return of their test equipment so that they could improve the design of the Sand Mantis eductor. 
WSRC-STI-2007-00189

This page intentionally left blank. 


\subsection{CONCLUSIONS AND RECOMMENDATIONS}

Screening tests of Sand Mantis candidate materials selected for erosion resistance have been completed. The results of this testing identified that over a relatively short period of operation ( $<1$ hour), measurable erosion will occur in each of the candidate zoom tube materials given equal operating exposure. Additionally, this testing has shown that erosion of the rubber discharge hose directly downstream of the vehicle could be expected to limit the service life of the discharge hose. Insufficient test experience was accumulated with the diamond nozzle insert to estimate a nozzle service life. On the basis of these test results, SRNL recommends the following;

- redesign of critical system components (e.g., zoom tube, discharge hose) should be conducted to improve system characteristics relative to erosion and capitalize on the results of this testing,

- continued efforts to deploy the Sand Mantis should include testing to better define and optimize operating parameters, and gain an understanding of system dynamics,

- discontinue wear testing with the selected materials pending redesign of critical system components ( $1^{\text {st }}$ recommendation) and inclusion of other candidate materials. The final selection of additional candidate materials should be made following design changes, but might include a Stellite alloy or zirconia. 
WSRC-STI-2007-00189

This page intentionally left blank. 


\subsection{REFERENCES}

1. WSRC-TR-2002-00052, “Characterization of Tank 19 Residual Waste”, J. L. Thomas and P. D. D’entremont, March 15, 2002.

2. HLE-TTR-2006-023, Rev. 0, Technical Task Request for Testing of TMR Sand Mantis HP Nozzles and Piping Materials Downstream of HP Nozzles

3. Krementz, D., "Task Technical and Quality Assurance Plan for Testing of TMR Sand Mantis High Pressure Nozzles and Piping Materials Downstream of High Pressure Nozzles” 23143-TTQAP, Rev. 0.

4. SRNL-MST-2007-00005, "Discharge Hose Breach during Sand Mantis Mockup Testing,” W. L. Daugherty, January 10, 2007.

5. “TMR Sand Mantis Characterization Tests,” January 12, 2007, summary notes from T. E. Skidmore maintained in Job Folder 23143.

6. "SAR Number Determination by ASTM G75-01 for Washington Savanna River Company.” J. D. Miller, White Rock Engineering Services, March 8, 2007.

7. WSRC-TR-93-595, "Potential for Erosion Corrosion of SRS High Level Waste Tanks," P. E. Zapp, January 1994.

8. "Erosion-Corrosion of Selected Metals in Coal Washing Plant Environments," G. R. Hoey and J. S. Bednar, Materials Performance, April 1983.

9. Goodyear hose products catalog

10. Corrosion Data Survey, $5^{\text {th }}$ Edition, N. E. Hamner, NACE, 1975.

11. "Erosion-Corrosion of Materials by Coal-Water Slurries," A. V. Levy and S. MacAdam, conference proceedings Material for Coal Gasification, Cincinnati Ohio, 10-15 October 1987. 
Distribution:

C. D. Banaszewski, 766-H

R. L. Bickford, 730-A

T. B. Caldwell, 766-H

T. B. Calloway, 999-W

N. F. Chapman, 766-H

W. L. Daugherty, 730-A

R. E. Eibling, 999-W

A. P. Fellinger, 730-A

J. R. Gordon, 730-A

D. J. Green, 773-A

J. C. Griffin, 773-A

E. K. Hansen, 999-W

B. R. Hess, 704-71F

J. P. Hyche, 766-H

K. J. Imrich, 773-A

N. C. Iyer, 773-41A

D. Krementz, 723-A

D. B. Little, 766-H

S. L. Marra, 773-A

K. D. Peterson, 773-A

T. E. Skidmore, 730-A

A. J. Tisler, 773-A

N. J. Vrettos, 730-A

Document Control, 703-43A 